\title{
Urate crystals directly activate the T-cell receptor complex and induce T-cell proliferation
}

\author{
THEODOROS ELEFTHERIADIS, GEORGIOS PISSAS, MARIA SOUNIDAKI, GEORGIA ANTONIADI, \\ IOANNIS TSIALTAS, VASSILIOS LIAKOPOULOS and IOANNIS STEFANIDIS
}

\author{
Department of Nephrology, Faculty of Medicine, University of Thessaly, Larissa, Thessaly 41110, Greece
}

Received April 12,2017; Accepted May 23, 2017

DOI: $10.3892 /$ br.2017.960

\begin{abstract}
Uric acid is a known danger associated molecular pattern molecule able to induce inflammation following internalization of its crystals by cells of the innate immune system. By activating antigen-presenting cells, urate boosts adaptive immunity as well. Furthermore, urate crystals can induce proliferation of isolated T-cells, which are unable to phagocytose crystal particles. In light of the evidence that urate crystals can also activate dendritic cells and macrophages without prior internalization but through sequestration of lipid rafts (and consequently receptors clustering in a non specific manner), the authors evaluated whether such a mechanism is involved in the direct activation of T-cells by urate crystals. In the present study, isolated human T-cells were cultured with or without urate at a concentration above its crystallization level. The expression and phosphorylation state of the T-cell receptor (TCR) complex zeta chain and the expression of the master regulator of cell proliferation c-Myc were assessed by western blotting. T-cell proliferation was measured by bromodeoxyuridine assay. Collectively, the results indicated that urate increased zeta chain phosphorylation indicating that it induces activation of TCR complex directly, since zeta chain phosphorylation takes place at the cell membrane and is a very proximal event in TCR complex-mediated signal transduction. In parallel, urate increased the expression of the transcription factor c-Myc and induced T-cell proliferation. In conclusion, urate crystals directly activate the TCR complex and induce T-cell proliferation.
\end{abstract}

\section{Introduction}

Uric acid, the end product of purine metabolism, is a well known danger associated molecular pattern (DAMP) molecule

Correspondence to: Professor Theodoros Eleftheriadis, Department of Nephrology, Faculty of Medicine, University of Thessaly, Neo Ktirio, Mezourlo Hill, Larissa, Thessaly 41110, Greece

E-mail: teleftheriadis@yahoo.com

Key words: uric acid, T-cells, T-cell receptor, zeta chain, c-Myc, proliferation as encountered in its crystallized form in the extracellular space. Urate functions as a DAMP through NOD-like receptor family, pyrin domain containing 3 (NLRP3) inflammasomedependent caspase- 1 activation and interleukin (IL) $-1 \beta$ production has been confirmed in experimental models such as the bleomycin-induced lung injury model (1), the acetaminophen-induced liver injury model (2), and importantly, in gout (3), the most well characterized urate-related clinical condition. Although the exact mechanisms involved in NALP3 activation remain to be elucidated, phagocytosis of urate crystals, fusion with lysosomes and subsequent rapture of the formed phagolysosomes and release of cathepsins or crystals, and reactive oxygen species production have been recognized as prerequisite steps (4).

By activating antigen presenting cells (APCs), urate crystals boost adaptive immunity as well. The last has been demonstrated in studies that have demonstrated that urate crystals acting as an adjuvant enhance antibody response following vaccination against hepatitis B surface antigen (5), tuberculosis (6) and tumors (7). It has been also proposed that aluminum hydroxide, the most widely adjuvant used in human vaccines, exerts its effect by activating dendritic cells through local cell injury and urate release (8).

Despite the fact that the effect of urate in boosting adaptive immunity indirectly by activating APCs is well documented, there are studies demonstrating that urate crystals are able to activate isolated T-cells in the absence of APCs (9-11), an unexpected event since T-cells are unable to phagocytose crystallized particles. However, there is evidence that urate crystals can be effective in activating intracellular events without previous internalization. More precisely, in dendritic cells urate crystals sequester lipid rafts and consequently aggregate their bound receptors. This non-specific clustering of receptors that contain immunoreceptor tyrosine-based activation motifs (ITAM) ultimately triggers an intracellular signal transduction cascade (12). In case of direct T-cell activation by urate crystals, the aforementioned model applied in dendritic cells becomes quite attractive. If urate crystals are able to aggregate lipid rafts in general, then they could cloister many TCR-complexes and co-receptors together, considering the fluidity of the membrane and the abundance of TCR-complexes and co-receptors in T-cells' lipid rafts $(13,14)$. Such a sequestration of receptors would eventually lead to T-cell activation. 
In the current study, the ability of urate crystals to activate directly TCR-complexes was assessed by evaluating the phosphorylation state of $\zeta$ chain. A $\zeta$-chain homodimer contains six ITAMs and is part of the TCR-complex $(15,16)$. Phosphorylation of $\zeta$-chain ITAMs is a crucial and very proximal event in signal transduction that normally starts immediately following the binding of the TCR on the surface of T-cell to the processed and presented with major histocompatibility complex antigen on the surface of APC $(17,18)$. In addition, the later outcome of TCR-complex activation, T-cell proliferation was assessed.

\section{Materials and methods}

Isolation and culture of T-cells. Blood samples were collected from 10 healthy volunteers (5 women/5 men, 25-46 years old). Informed consent was obtained from each individual enrolled into the study and the Ethics Committee of the Faculty of Medicine, University of Thessaly (Larissa, Greece) approved the study protocol.

Peripheral blood mononuclear cells (PBMCs) were isolated from blood by Ficoll-Hypaque density gradient centrifugation (Histopaque 1077; Sigma-Aldrich; Merck KGaA, Darmstadt, Germany). T-cells were isolated from the PBMCs by negative selection. Non T-cells were indirectly magnetically labeled with a cocktail of biotin-conjugated monoclonal antibodies and were depleted using the Pan T-cell Isolation kit (Miltenyi Biotec GmbH, Bergisch Gladbach, Germany). The purity of the isolated T-cells was tested and confirmed by means of flow cytometry. Isolated T-cells were counted on a Neubauer chamber with an optical microscope, and cell viability was assessed using the trypan blue exclusion assay (Sigma-Aldrich; Merck KGaA).

T-cells were resuspended in RPMI-1640 medium with L-glutamine and $10 \mathrm{mM}$ HEPES (Sigma-Aldrich; Merck $\mathrm{KGaA}$ ) and supplemented with $10 \%$ fetal bovine serum (Sigma-Aldrich; Merck KGaA) and antibiotic-antimycotic solution (Sigma-Aldrich; Merck KGaA). T-cells were cultured for $48 \mathrm{~h}$ at a density of $1 \times 10^{6}$ cells/well in 12 well-plates or $1 \times 10^{5}$ cells/well in 96 well-plates. Cells were cultured with or without urate at a concentration of $10 \mathrm{mg} / \mathrm{dl}$ (Sigma-Aldrich; Merck KGaA). This concentration is above the concentration of $6.7 \mathrm{mg} / \mathrm{dl}$ at which uric acid is crystallized, yet still within the levels observed in hyperuricemic patients (19). As expected, at the used concentration urate was precipitated forming monosodium urate crystals. Cultures were incubated at $37^{\circ} \mathrm{C}$ in an atmosphere of $95 \%$ relative humidity and $5 \% \mathrm{CO}_{2}$.

Assessment of $\zeta$-chain, its phosphorylation state and c-Myc levels. Cells were lysed using the T-PER tissue protein extraction reagent (Thermo Fisher Scientific, Inc., Waltham, MA, USA) supplemented with protease and phosphatase inhibitors (Sigma-Aldrich; Merck KGaA and Roche Diagnostics, Basel, Switzerland, respectively). Protein was quantified via Bradford assay (Sigma-Aldrich; Merck KGaA) and $10 \mu \mathrm{g}$ from each sample were used for western blotting. Blots were incubated with the primary antibody for $16 \mathrm{~h}$, followed by the secondary antibody incubation for $30 \mathrm{~min}$. In case of re-probing polyvinylidene difluoride blots, the previous primary and secondary antibody were removed via the use of the Restore Western Blot

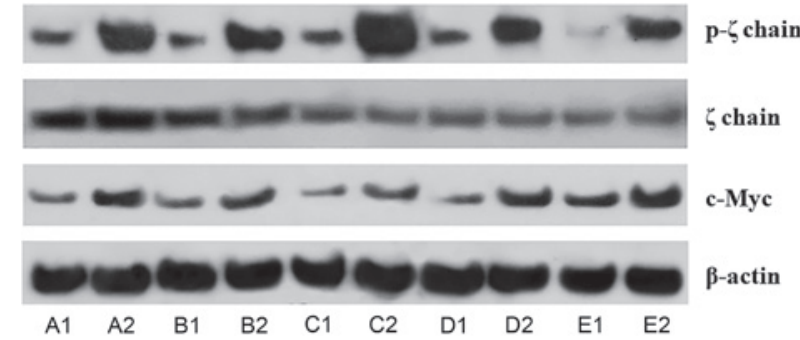

Figure 1. Western blot analysis of $\zeta$-chain, $\mathrm{p}-\zeta$-chain and c-Myc in isolated T-cells treated with or without urate. Isolated T-cells were cultured for $48 \mathrm{~h}$ in the presence or not of urate at a concentration of $10 \mathrm{mg} / \mathrm{dl}$. Then proteins were extracted and western blotting performed for assessing the levels of $\zeta$-chain, $\mathrm{p}-\zeta$-chain and c-Myc. The results of five of the 10 performed experiments are depicted. Capital letters correspond to lymphocytes derived from different individuals (subjects A-E). 1 represents control lanes and 2 represents T cell cultures in the presence of urate.

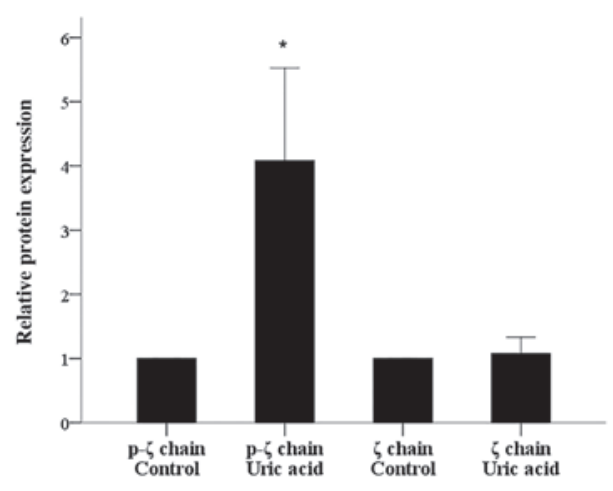

Figure 2. Urate does not affect $\zeta$-chain expression but increases its phosphorylation. In isolated T-cells, the presence of urate at a concentration of 10 $\mathrm{mg} / \mathrm{dl}$ did not affect $\zeta$-chain expression; however it increased its phosphorylation state significantly. ${ }^{*} \mathrm{P}<0.05$ vs. respective control. Values are presented as mean \pm standard deviation

Stripping Buffer (Thermo Fisher Scientific Inc.) according to the manufacturer's protocol. Blots were analyzed using the Image J software (version 1.49; National Institutes of Health, Bethesda, MD, USA).

The primary antibodies used in western blotting were specific for $\zeta$-chain (rabbit polyclonal antibody; dilution 1:1,000; cat. no. sc-20919; Santa Cruz Biotechnology, Inc., Dallas, TX, USA), phosphorylated $\zeta$-chain (mouse monoclonal antibody; dilution 1:1,000; cat. no. sc-9975; Santa Cruz Biotechnology, Inc.), c-Myc (rabbit monoclonal antibody; dilution 1:1,000; cat. no. 9402; Cell Signaling Technology, Inc., Danvers, MA, USA) and $\beta$-actin (dilution 1:5,000; cat. no. 4967; Cell Signaling Technology, Inc.). The secondary antibodies were anti-mouse IgG, horseradish-peroxidase (HRP)-linked antibody (cat. no. A9044; dilution 1:1,000; Sigma-Aldrich; Merck KGaA) and anti-rabbit IgG, HRP-linked antibody (cat. no. 7074; Cell Signaling Technology, Inc.).

Assessment of T-cell proliferation. T-cell proliferation was assessed by Cell Proliferation ELISA (cat. no. 11669915001; Roche Diagnostics) using bromodeoxyuridine (BrdU) labelling and immunoenzymatic detection according to the manufacturer's protocol. Proliferation index was calculated by 
A

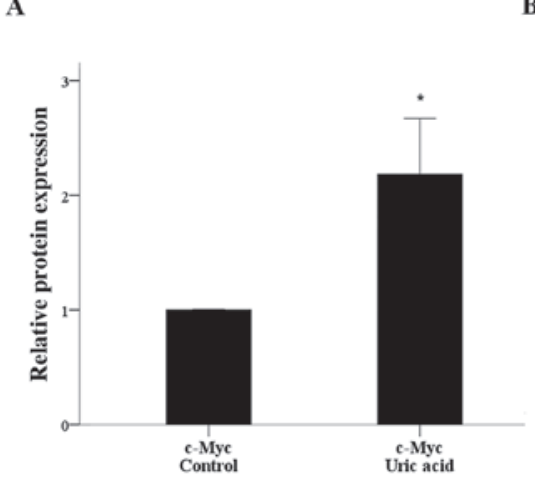

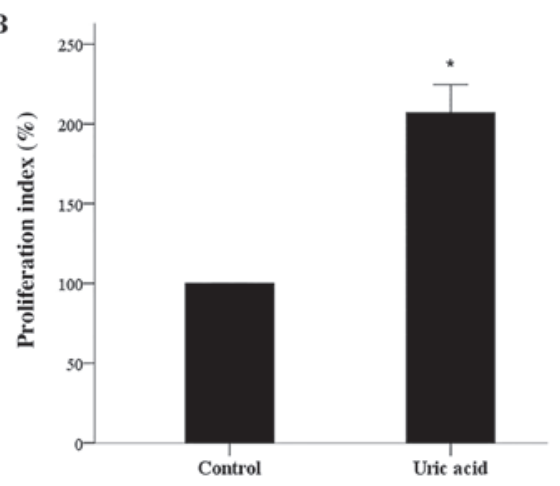

Figure 3. Urate increases c-Myc expression and induces T-cell proliferation. (A) In isolated T-cells, the presence of urate at a concentration of 10 mg/dl increased the expression of the master regulator of T-cell proliferation transcription factor c-Myc significantly. (B) In parallel, urate induced T-cell proliferation. ${ }^{*} \mathrm{P}<0.05$ vs. respective control. Values are presented as mean \pm standard deviation.

the equation Proliferation index $(\%)=($ optical density $(\mathrm{OD})$ derived from cultures with urate/OD derived from cultures without urate) x 100. All these experiments were performed in triplicate and the results refer to the mean of the three measurements.

Statistical analysis. Normality of the evaluated variables was assessed and confirmed by one-sample Kolmogorov-Smirnov test. For comparison of means paired t-test was used. Results were expressed as mean \pm standard deviation and a $\mathrm{P}<0.05$ was considered to indicate statistically significant difference.

The P-values were calculated by comparing the means of OD derived either form BrdU ELISA or from western blot analysis. Statistical analysis following normalization to the controls' OD values was avoided in order to prevent violation of the prerequisite for normal distribution of the compared variables when applying parametric statistical tests. However, for reader's convenience, the results were expressed and depicted following normalization of means for the control group according to the equation: Relative OD=OD from each culture $\div$ OD from the respective cultures without urate.

\section{Results}

Urate did not affect $\zeta$-chain expression but it increased its phosphorylation significantly. Urate crystals did not affect $\zeta$-chain expression in isolated T-cells since its expression altered only by a factor of $1.08 \pm 0.26(\mathrm{P}=0.447$; Figs. 1 and 2$)$. On the contrary, urate crystals induced $\zeta$-chain phosphorylation significantly. In isolated T-cells cultured with urate at a concentration of $10 \mathrm{mg} / \mathrm{dl}$, the level of phosphorylated $\xi$-chain $(\mathrm{p}-\zeta)$ increased by a factor of $4.08 \pm 1.44(\mathrm{P}<0.001$; Figs. 1 and 2).

Urate increased the expression of $c$-Myc significantly. Culture of isolated T-cells in the presence of urate at a concentration of $10 \mathrm{mg} / \mathrm{dl}$ increased the expression of the master regulator of T-cell proliferation transcription factor c-Myc 2.18 \pm 0.49 times $(\mathrm{P}<0.001$; Figs. 1 and 3A).

Urate induced T-cell proliferation. In isolated T-cells treated with $10 \mathrm{mg} / \mathrm{dl}$ urate, the increase in c-Myc expression was accompanied by increased cell proliferation. Compared to untreated isolated T-cells, isolated T-cells cultured with urate exhibited a proliferation index increased by $206.98 \pm 8.79 \%$ (Fig. 3B).

\section{Discussion}

Triggered by studies that have indicated that urate crystals are able to activate isolated T-cells (9-11), which are unable to phagocytose crystal particles, the authors evaluated whether urate is able to activate directly the TCR-complex. The rationale behind this attempt was based on the fact that the TCR-complex and other co-receptors lie within lipid rafts in cell membrane $(13,14)$, and, at least in dendritic cells, urate crystals by sequestering lipid rafts they bring together ITAM containing receptors resulting in their activation and the initiation of intracellular signal transduction events (12). This potential of urate crystals to activate cells through nonspecific clustering of cell membrane receptors due to lipid raft sequestration has been confirmed in macrophages as well, in which they induce NALP3 activation (20). Interestingly, other crystals share this property of urate crystals. Alum, the widest used adjuvant in human vaccines, activates dendritic cells by inducing lipid rafts sequestration (21). This property of alum crystals has been also confirmed in a biophysical study of lipid domain clustering in a simple model of phospholipid monolayers containing dipalmitoyl-phosphatidylcholine and dioleoyl-phosphatidylcholine (22). Calcium phosphate crystals (23), as well as poly methyl-methacrylate microspheres of $153 \mu \mathrm{m}$ diameter (24), impossible to be phagocytosed, are also able to activate macrophages by inducing lipid rafts clustering. A similar mechanism may be responsible for innate immune cells activation by cholesterol or heme crystals, since in both cases activation can take place in the absence of phagocytosis $(25,26)$. It is remarkable that urate crystals are also able to affect non immune system cells, and more precisely to induce apoptosis in osteoblasts, independently of phagocytosis (27). Thus, it is likely that many crystal structures are able to affect cell function by sequestering cell membrane lipid rafts.

In the current study, the ability of urate crystals to act in a similar way in T-cells and consequently activate the TCR-complex in a non specific and antigen independent manner was evaluated by assessing the phosphorylation status $\zeta$-chain. This $16 \mathrm{kD}$ protein is an indispensable component of 
the TCR-complex and its phosphorylation is the first event that occurs after TCR activation (15-18). Indeed, western blotting revealed that urate crystals did not affect $\zeta$-chain expression following $48 \mathrm{~h}$ of isolated T-cells culture, but they increased its phosphorylation significantly. Thus, urate crystals activate the TCR-complex directly likely by inducing lipid raft clustering.

Next, the authors evaluated if urate crystals are able to induce later effects of TCR-complex activation, and more precisely $\mathrm{T}$-cell proliferation. Indeed, urate crystals increased the expression of the transcription factor c-Myc. This transcription factor serves a pivotal role in T-cell proliferation and controls metabolic reprogramming upon T-cell activation $(28,29)$. Expression of c-Myc decreased in case of decreased $\zeta$-chain expression (30), as well as of reduced phosphorylation of the TCR-complex ITAM (31). In parallel with increase of c-Myc expression, urate crystals increased T-cell proliferation.

Since activation of the TCR-complex without co-stimulation by activation of co-receptors, such as CD28, results in T-cell anergy $(32,33)$, it is possible that urate crystals sequesters lipid rafts containing both TCR-complexes and co-receptors in order to achieve full T-cell activation and proliferation. Another possibility may reside in the ability of urate crystals to induce active IL- $1 \beta$ production in a NALP3-dependent manner. The fact that, in isolated T-cells cultured with urate crystals, inhibition of NALP3 abrogates both IL-1 $\beta$ production and T-cell proliferation (9), favors such a possibility. The first transcription factors that are activated upon full T-cell activation are the nuclear factor of activated $\mathrm{T}$ cells (NFAT), nuclear factor $(\mathrm{NF})-\kappa \mathrm{B}$ cells and activator protein 1 (AP1). Especially for activation of AP1 co-stimulation is required; otherwise T-cell falls in a state of anergy $(32,33)$. The cytokine IL-1 $\beta$ activates AP1 and NF- $\kappa B$ (34). Consequently, IL-1 $\beta$ may provide the additional to NFAT $(32,33)$, which is activated by the TCR-complex, transcription factor AP1 leading to full T-cell activation even in the absence of co-stimulation.

According to the results of the present study, one could assume that hyperuricemia may result in T-cell activation. However, this aspect requires further investigation. Certainly, an acute raise in extracellular urate levels due to any tissue damage may enhance T-cell immune response both indirectly by activating APCs $(1-3,8)$, and according to this and other studies directly (9-11). Nevertheless, in the chronic hyperuricemic state, the opposite may occur since chronic inflammation (30,35-37), or TCR-complex activation $(17,18)$, resulting in $\zeta$-chain downregulation.

In conclusion, the results of the present study support that urate crystals are able to activate the TCR-complex directly and induce T-cell proliferation, expanding the known immune cell targets of urate and supporting its phagocytosis-independent way of action.

\section{References}

1. Gasse P, Riteau N, Charron S, Girre S, Fick L, Pétrilli V, Tschopp J, Lagente V, Quesniaux VF, Ryffel B, et al: Uric acid is a danger signal activating NALP3 inflammasome in lung injury inflammation and fibrosis. Am J Respir Crit Care Med 179: 903-913, 2009.

2. Kono H, Chen CJ, Ontiveros F and Rock KL: Uric acid promotes an acute inflammatory response to sterile cell death in mice. J Clin Invest 120: 1939-1949, 2010.
3. Busso $\mathrm{N}$ and So A: Microcrystals as DAMPs and their role in joint inflammation. Rheumatology (Oxford) 51: 1154-1160, 2012.

4. Rock KL, Kataoka H and Lai JJ: Uric acid as a danger signal in gout and its comorbidities. Nat Rev Rheumatol 9: 13-23, 2013.

5. Ma XJ, Tian DY, Xu D, Yang DF, Zhu HF, Liang ZH and Zhang ZG: Uric acid enhances $T$ cell immune responses to hepatitis B surface antigen-pulsed-dendritic cells in mice. World J Gastroenterol 13: 1060-1066, 2007.

6. Taus F, Santucci MB, Greco E, Morandi M, Palucci I, Mariotti S, Poerio N, Nisini R, Delogu G and Fraziano M: Monosodium Urate Crystals Promote Innate Anti-Mycobacterial Immunity and Improve BCG Efficacy as a Vaccine against Tuberculosis. PLoS One 10: e0127279, 2015.

7. Wang Y, Ma X, Su C, Peng B, Du J, Jia H, Luo M, Fang C and Wei Y: Uric acid enhances the antitumor immunity of dendritic cell-based vaccine. Sci Rep 5: 16427, 2015.

8. Kool M, Soullié T, van Nimwegen M, Willart MA, Muskens F, Jung S, Hoogsteden HC, Hammad H and Lambrecht BN: Alum adjuvant boosts adaptive immunity by inducing uric acid and activating inflammatory dendritic cells. J Exp Med 205: 869-882, 2008.

9. Eleftheriadis T, Pissas G, Antoniadi G, Makri P, Liakopoulos V and Stefanidis I: Urate crystals induce NLRP3 inflammasomedependent IL-1 $\beta$ secretion and proliferation in isolated primary human T-cells. Hippokratia 19: 41-46, 2015.

10. Eleftheriadis T,Pissas G, Karioti A,Antoniadi G, Golfinopoulos S, Liakopoulos V, Mamara A, Speletas M, Koukoulis G and Stefanidis I: Uric acid induces caspase-1 activation, IL-1 $\beta$ secretion and $\mathrm{P} 2 \mathrm{X} 7$ receptor dependent proliferation in primary human lymphocytes. Hippokratia 17: 141-145, 2013.

11. Webb R, Jeffries M and Sawalha AH: Uric acid directly promotes human T-cell activation. Am J Med Sci 337: 23-27, 2009.

12. Ng G, Sharma K, Ward SM, Desrosiers MD, Stephens LA Schoel WM, Li T, Lowell CA, Ling CC, Amrein MW, et al: Receptor-independent, direct membrane binding leads to cellsurface lipid sorting and Syk kinase activation in dendritic cells. Immunity 29: 807-818, 2008 .

13. Dinic J, Riehl A, Adler J and Parmryd I: The T cell receptor resides in ordered plasma membrane nanodomains that aggregate upon patching of the receptor. Sci Rep 5: 10082, 2015.

14. Varshney P, Yadav V and Saini N: Lipid rafts in immune signalling: Current progress and future perspective. Immunology 149: 13-24, 2016.

15. Samelson LE, Harford JB and Klausner RD: Identification of the components of the murine $\mathrm{T}$ cell antigen receptor complex. Cell 43: 223-231, 1985.

16. Reth M: Antigen receptor tail clue. Nature 338: 383-384, 1989.

17. Chan AC, Desai DM and Weiss A: The role of protein tyrosine kinases and protein tyrosine phosphatases in $\mathrm{T}$ cell antigen receptor signal transduction. Annu Rev Immunol 12: 555-592, 1994.

18. Eleftheriadis T, Antoniadi G, Liakopoulos V and Kortsaris A: T-Cell Zeta Chain Expression, Phosphorylation and Degradation and their Role in T-Cell Signal Transduction and Immune Response Regulation in Health And Disease. Curr Signal Transduct Ther 1: 191-208, 2006.

19. Richette P, Doherty M, Pascual E, Barskova V, Becce F, Castañeda-Sanabria J, Coyfish M, Guillo S, Jansen TL, Janssens H, et al: 2016 updated EULAR evidence-based recommendations for the management of gout. Ann Rheum Dis 76: 29-42, 2017.

20. Hari A, Zhang Y, Tu Z, Detampel P, Stenner M, Ganguly A and Shi Y: Activation of NLRP3 inflammasome by crystalline structures via cell surface contact. Sci Rep 4: 7281, 2014.

21. Flach TL, Ng G, Hari A, Desrosiers MD, Zhang P, Ward SM, Seamone ME, Vilaysane A, Mucsi AD, Fong Y, et al: Alum interaction with dendritic cell membrane lipids is essential for its adjuvanticity. Nat Med 17: 479-487, 2011.

22. Antúnez LR, Livingston A, Berkland C and Dhar P: Physiochemical Properties of Aluminum Adjuvants Elicit Differing Reorganization of Phospholipid Domains in Model Membranes. Mol Pharm 13: 1731-1737, 2016.

23. Corr EM, Cunningham CC, Helbert L, McCarthy GM and Dunne A: Osteoarthritis-associated basic calcium phosphate crystals activate membrane proximal kinases in human innate immune cells. Arthritis Res Ther 19: 23, 2017.

24. Malik AF, Hoque R, Ouyang X, Ghani A, Hong E, Khan K, Moore LB, Ng G, Munro F, Flavell RA, et al: Inflammasome components Asc and caspase-1 mediate biomaterial-induced inflammation and foreign body response. Proc Natl Acad Sci USA 108: 20095-20100, 2011. 
25. Corr EM, Cunningham CC and Dunne A: Cholesterol crystals activate Syk and PI3 kinase in human macrophages and dendritic cells. Atherosclerosis 251: 197-205, 2016.

26. Dutra FF, Alves LS, Rodrigues D, Fernandez PL, de Oliveira RB, Golenbock DT, Zamboni DS and Bozza MT: Hemolysis-induced lethality involves inflammasome activation by heme. Proc Natl Acad Sci USA 111: E4110-E4118, 2014.

27. Chhana A, Callon KE, Pool B, Naot D, Watson M, Gamble GD, McQueen FM, Cornish J and Dalbeth N: Monosodium urate monohydrate crystals inhibit osteoblast viability and function: Implications for development of bone erosion in gout. Ann Rheum Dis 70: 1684-1691, 2011.

28. Wang R, Dillon CP, Shi LZ, Milasta S, Carter R, Finkelstein D, McCormick LL, Fitzgerald P, Chi H, Munger J, et al: The transcription factor Myc controls metabolic reprogramming upon $\mathrm{T}$ lymphocyte activation. Immunity 35: 871-882, 2011.

29. Chou C and Egawa T: Myc or no Myc, that is the question. EMBO J 34: 1990-1991, 2015.

30. Eleftheriadis T, Pissas G, Antoniadi G, Tsogka K, Sounidaki M, Liakopoulos V and Stefanidis I: Indoleamine 2,3 dioxygenase downregulates $\mathrm{T}$ cell receptor complex $\zeta$ chain and $\mathrm{c}$ Myc, and reduces proliferation, lactate dehydrogenase levels and mitochondrial glutaminase in human T cells. Mol Med Rep 13 925-932, 2016

31. Guy CS, Vignali KM, Temirov J, Bettini ML, Overacre AE, Smeltzer M, Zhang H, Huppa JB, Tsai YH, Lobry C, et al: Distinct TCR signaling pathways drive proliferation and cytokine production in T cells. Nat Immunol 14: 262-270, 2013.
32. Fathman CG and Lineberry NB: Molecular mechanisms of CD4 ${ }^{+}$ T-cell anergy. Nat Rev Immunol 7: 599-609, 2007.

33. Nurieva RI, Liu X and Dong C: Molecular mechanisms of T-cell tolerance. Immunol Rev 241: 133-144, 2011.

34. Barksby HE, Lea SR, Preshaw PM and Taylor JJ: The expanding family of interleukin-1 cytokines and their role in destructive inflammatory disorders. Clin Exp Immunol 149: 217-225, 2007.

35. Rodriguez PC, Zea AH, DeSalvo J, Culotta KS, Zabaleta J, Quiceno DG, Ochoa JB and Ochoa AC: L-arginine consumption by macrophages modulates the expression of $\mathrm{CD} 3$ zeta chain in T lymphocytes. J Immunol 171: 1232-1239, 2003.

36. Bronstein-Sitton N, Cohen-Daniel L, Vaknin I, Ezernitchi AV, Leshem B, Halabi A, Houri-Hadad Y, Greenbaum E, Zakay-Rones Z, Shapira L, et al: Sustained exposure to bacterial antigen induces interferon-gamma-dependent $\mathrm{T}$ cell receptor zeta down-regulation and impaired $\mathrm{T}$ cell function. Nat Immunol 4: 957-964, 2003.

37. Eleftheriadis T, Kartsios C, Yiannaki E, Kazila P, Antoniadi G, Liakopoulos V and Markala D: Chronic inflammation and T cell zeta-chain downregulation in hemodialysis patients. Am J Nephrol 28: 152-157, 2008. 